\title{
Mentor suitability and mentoring relationship quality: lessons from the Glasgow Intergenerational Mentoring Network
}

Katie McArthur, University of Strathclyde

Alastair Wilson, University of Strathclyde

Katie Hunter, University of Strathclyde

This is a peer-review, accepted author manuscript of the following article: McArthur, K., Wilson, A., \& Hunter, K. (2017). Mentor suitability and mentoring relationship quality: lessons from the Glasgow Intergenerational Mentoring Network. Journal of Community Psychology. (In press) 
Running head: Mentor suitability and relationship quality.

The research literature on mentoring is diverse, draws mainly on studies from the US and spans youth, academic and workplace mentoring (Eby et al, 2010). School-based mentoring programmes targeted at socially disadvantaged young people vary from those employing peer mentors, older students and adults of different ages, and show modest positive impacts on outcomes such as truancy, misconduct and academic abilities (Rhodes et al., 2005). A meta-analysis of 73 US mentoring programmes (DuBois et al, 2011) suggested overall effectiveness showing positive outcomes for young people across social, emotional, academic and behavioural domains, and positioning mentoring as having equal effectiveness compared with other forms of youth intervention. Furthermore, the findings showed that young people not engaged in mentoring declined over time on similar outcomes.

However, a body of evidence from US studies challenges the assumption that mentoring is universally beneficial to young people (Grossman \& Rhodes, 2002; Rhodes \& DuBois, 2008). In fact, up to $50 \%$ of youth mentoring relationships end prematurely (Rhodes, 2002), and these premature endings are potentially harmful to young people, and more likely to be harmful for more vulnerable youth (Grossman \& Rhodes, 2002; Karcher, 2005). There may be a relationship between the level of vulnerability of a young person and the outcome of mentoring whereby more vulnerable youth are less likely to establish a strong mentoring relationship. For instance, Soucy and Larose (2000) report that young people who had greater security in their relationships with their mothers developed more beneficial relationships with mentors. By contrast, young people who have been referred for psychological treatment are less likely to sustain relationships with mentors (Grossman \& Rhodes, 2002). It may be that young people who have more difficult familial relationships struggle to initially establish a strong bond with an adult mentor, but where these 
relationships are established, the interpersonal benefits are greater. Rhodes et al (2009) found evidence that young people in foster care who were mentored experienced more positive effects on their relationships with others. This points to the importance of a mentor's commitment to the relationship, and willingness to persevere despite the potential for a difficult beginning, which is key to avoiding further harm to already vulnerable young people who may experience the end of a mentoring relationship as an abandonment.

To address this risk, Rhodes, Liang and Spencer (2009) published a set of ethical principles for youth mentoring relationships. In this article, they highlight that unrealistically positive assumptions about the benefits of mentoring often leads programme administrators and funders to focus on expansion, measuring success according to quantity, as opposed to quality (for instance, devoting resources to new matches at the expense of supporting existing ones). The authors argue that recognising the potential risk of child abuse, which occurs infrequently in mentoring programs (Saul \& Audage, 2007), is not sufficient to protect young people from more subtle negative experiences with mentoring, including premature endings, which lead to feelings of disappointment, rejection and betrayal (e.g. Spencer, 2007) and poor emotional, behavioural and academic outcomes (Downey, Lebolt, Rincon \& Freitas, 1998). For example, two large US studies which employed random assignment showed that for young people who experience the premature ending of a mentoring relationship, incidence of problem behaviours increased (Grossman \& Rhodes, 2002; Herrera et al, 2007).

Rhodes, Liang \& Spencer (2009) based their ethical guidelines for youth mentoring on their own research and experience as well as the American Psychological Association's (APA, 2002) Ethical Principles of Psychologists and Code of Conduct, which is itself based on research findings and practice in the field of psychology. While acknowledging that 
Running head: Mentor suitability and relationship quality.

mentoring relationships are distinct from therapeutic relationships, they highlight that both types of relationship constitute "a human connection whose explicit goal is to foster the positive development of one of the partners" (p.453; Rhodes, Liang \& Spencer, 2009).

This psychosocial approach whereby mentoring even in an educational context is not a purely educational task, may be particularly appropriate for socio-economically disadvantaged young people. The World Health Organization defines mental health as 'a state of wellbeing in which the individual realizes his or her own abilities, can cope with the normal stresses of life, can work productively and fruitfully, and is able to make a contribution to his or her community' (WHO, 2010). However, research shows that poverty leads to feelings that prevent individuals from improving their life circumstances (Bandura \& Locke, 2003) and that interventions are necessary to foster empowerment, self-esteem and self-efficacy and to reduce isolation (Callahan \& Lumb, 1995). Attempting to further the educational and vocational aims of young people without attending to their socio-emotional context may be counter-productive.

The mentoring relationship

Existing literature on mentoring indicates that in order to have benefits for young people, mentoring relationships should be sustained for 6-12 months (Garringer et al., 2003) and that those lasting more than a year have the greatest chance of showing positive changes in academic and psychosocial outcomes (Grossman \& Rhodes, 2002). Keller (2005) supports this indicating that 'mentors frequently note an initial period in the relationship, sometimes 6 months to a year in length, when the youth is reluctant to trust the mentor, is uncommunicative, and may fail to keep appointments or return phone calls'. While there 
may be variation between projects, research indicates that significant time investment is required, and 1-2 hours contact time per week for a school year is recommended as a minimum (Spencer, 2006; CPRD, 2009). The quality of mentoring relationships may be a key determinant of the success or otherwise of a mentoring project (Rhodes \& DuBois, 2008). Indeed, mentoring relationship quality (MRQ) has been identified as a priority for research in order to understand variations in effectiveness between projects (Larose, Savoie, DeWit, Lipman \& DuBois, 2015; Rhodes \& DuBois, 2008). While mentoring relationship quality is determined by both partners, this article focuses on variation between mentors in terms of suitability for the role. Some volunteer mentors are more effective than others, and across approaches, the relationship seems to be a predictor of positive outcome. Some work has already been done on researching mentoring relationship quality. Notably, Pryce (2012) has conceptualised mentors in terms of their 'attunement' - ranging from highly attuned to minimally attuned - to understand the differences in quality between mentoring relationships.

The Glasgow Intergenerational Mentoring Network

This article draws on data from a research and development project, the Glasgow Intergenerational Mentoring Network. It aims to explore, with reference to case studies of real mentoring relationships, the nature of the mentoring role from the mentor's perspective. Interviews were conducted with volunteer mentors throughout their relationships with young people focusing on their experience of mentoring, and mentors were also asked to provide regular progress updates to research and development staff in order to flag up any problems. By exploring the approaches of mentors who were involved in relationships with varying degrees of success, this article aims to clarify the aspects that promote close relationships in mentoring. Sustaining a mentoring relationship for one school year or longer is itself taken as 
Running head: Mentor suitability and relationship quality.

an indicator of success, and in addition, the research and development team draw on informal reports from both teaching staff and the young people involved. Due to continued contact with relevant staff and mentees, as well as regular updates from mentors, the research and development team were able to monitor mentoring relationships. Mentor interviews have been analysed with a view to which practices were linked to problematic relationships and which were associated with mentoring progressing as planned.

\section{Research Questions}

- What aspects of mentoring are likely to promote the quality of a mentoring relationship?

- What impact is an individual mentor's relational capacity likely to have on the success of a mentoring relationship?

- What are the implications of variations in mentor relational capacity for recruitment, training and support of volunteer mentors?

\section{Mentor recruitment}

Volunteers were recruited from university alumni using an email advertising the Glasgow Intergenerational Mentoring Network, and providing a link to an online application form. An initial mentor recruitment interview was conducted with each applicant by two members of the research and development team, lasting approximately one hour. This meeting involved explaining the project as fully as possible and ensuring the volunteer was able to commit to the following:

- continued involvement in the project for at least one school year 
- weekly or fortnightly meetings with a young person

- any necessary travel time to and from school

- participation in the research and development process.

\begin{abstract}
At this stage, researchers also explored volunteers' professional backgrounds and any specific skills or experience in working with young people. Past experience of mentoring junior members of their profession was taken into account, as was informal mentoring of young people (such as the applicant's own children or relatives). Those who were considered appropriate for the project then completed the PVG application process and attended brief training which included input on the mentoring relationship based on the recommendations generated from research on youth mentoring, and specific information on child protection procedures.
\end{abstract}

The project so far has shown that mentoring a socially disadvantaged young person is a complex social situation which mentors must adapt to by becoming familiar with the young person's frame of reference, instead of imposing their own ideas about social disadvantage and educational success. The more vulnerable the young person, the more expertise is required on the part of the mentor, and this is where the capacity of the volunteer mentor to adapt to the unique relationship they find themselves in comes to the fore. In cases where mentors are less willing or able to adjust their preconceived ideas of social disadvantage, more support is needed from the research and development team in order to maintain mentoring relationships.

Mentee induction 
Running head: Mentor suitability and relationship quality.

In each school, a member of the research team presented the project to a small group of S5 pupils (generally 10-15 pupils per school) who had been identified by teaching staff as potentially appropriate for the project aims relating to widening participation in Higher Education (i.e. usually pupils who were aiming to sit five Highers in S5). This meeting included a general discussion of progressing to Higher Education from school, the rationale for mentoring, the voluntary nature of the project, and their positive and negative expectations of having a mentor. The project aims and their potential involvement was explained in full, with opportunities to ask questions. Interested pupils then met with a member of the research team individually to discuss their level of motivation to take part, their career ideas, any other interests and any specific preferences in terms of being matched with a mentor (e.g. gender preference). In addition, any other information provided by teaching staff was taken into account by the research team to build a picture of each young person to aid in the matching process.

\section{Matching}

Based on knowledge of volunteer mentors and young people, matches were made through discussion within the research team of aspects including career interests, personal qualities, expressed preferences, and practical concerns such as geographical location and schedules. Decisions were made on a case by case basis and depended largely on whether the young person had decided on a specific career path or were open to wider possibilities. For instance, young people with aspirations to enter specific competitive courses such as medicine and law were matched primarily on this basis, while other interests and personality factors may have played a bigger part in matching young people whose aspirations were broader or undecided. 


\section{Mentor suitability}

One of the key lessons learned during this process relates to the suitability of specific volunteers for the mentoring role. In some cases, young people may have been less engaged in the mentoring relationship despite a high level of skill on the part of the mentor. However, in instances where the young person did engage readily with the mentoring relationship, its success depended on the mentor. The research team observed that given a level of engagement on the part of the young person, mentors who were able to adapt to the specific needs of their mentee tended to build strong relationships. Due to the centrality of the human relationship between mentor and mentee, the success of each match was dependant on a multitude of factors which are difficult to delineate. However, some patterns emerged which allowed the research team to draw conclusions as to the best way of recruiting, training and supporting volunteer mentors, and the factors to consider when matching. Pryce (2012) identifies three categories of mentor: 'highly attuned', 'moderately attuned' and 'minimally attuned' mentors, highlighting the responsibility of the mentor in establishing a strong working relationship with a mentee. These categories map reasonably well on to the experience of the Glasgow Intergenerational Mentoring Network, indicating that an appropriate strategy in coordinating similar mentoring projects would be to focus on recruiting highly attuned individuals as volunteer mentors. In addition, the research team observed an interaction between a volunteer's level of relational attunement and previous experience working with young people, such that different categories of mentor emerged from this project representing a spectrum of adaptability to the mentoring role. For the purposes of this article, we have labelled the three categories relational experts, relational learners and non-relational mentors, and illustrated each with case material taken from mentor notes and research interviews with mentors. 
Running head: Mentor suitability and relationship quality.

\section{Ethical considerations}

The research and development work conducted as part of the Glasgow Intergenerational Mentoring Network has been approved by the relevant University Ethics Committee. In relation to confidentiality, case material presented here is organised to preserve the anonymity of mentors and mentees. Certain identifying details have been changed, and other similar cases have been amalgamated into more general case studies so that they describe types of mentoring relationship observed by the research team, rather than reporting directly on specific individuals.

\section{Relational experts}

One clear subset of volunteer mentors emerged who could be described as 'relational experts' - volunteers who possess a high level of relational skill in supporting young people as well as confidence in their ability to do so. These individuals may have come from professional backgrounds like social work, teaching and counselling, and may have had professional or personal experience of working with vulnerable youth and/or social disadvantage. This finding is in line with one study which suggested that previous experience in a helping role contributes to effectiveness in e-mentoring (Shpigelman \& Gill, 2013). The common factor among relational expert mentors in this project was that they entered the mentoring relationship with an understanding of relevant issues such as poverty and its impact on mental health. They were adaptable to the needs of individual young people, and able to work independently and flexibly, making decisions as to how to manage the mentoring relationship without explicit direction from the research team. In developing a 
model of ethical and effective evidence-based mentoring, recruitment of these relational expert mentors is an excellent strategy. Targeting volunteers with existing skills in mental health and social work, already comfortable and competent in building a supportive relationship with a young person, should be the bedrock of any mentoring project. These mentors tend to establish strong and lasting connections with mentees which are of benefit, and require little support from project staff. As part of a community of volunteer mentors, these individuals also make an invaluable contribution to ongoing training and support.

\section{Anne and Robert}

One relational expert mentor was Anne, a counsellor and English graduate who also worked at an academic institution focusing on the arts. She was matched with Robert, an S5 pupil who was primarily interested in an arts-based teacher training course at Anne's institution and, at the time of their first meeting, concerned about attaining the necessary grade in his English Higher. During their work together, Robert obtained his English Higher, applied for the course, and was invited to interview. He was unsuccessful at interview, and was offered a place at another University to study for an arts degree, which had been his second choice. Anne used counselling skills to develop a strong relationship with Robert, and support his decision making processes non-judgementally. They moved through goal-based stages according to Robert's changing priorities including working on English coursework, writing a personal statement, and practicing for the course interview. Anne's role also involved debriefing with Robert at key moments. For instance, two key turning points for Robert occurred during the mentoring relationship: first when he obtained the English Higher required to apply for his preferred course, and then later following his unsuccessful interview. Anne was able to adapt to these changes in momentum, and support his decision making process while respecting his autonomy. Discussing the tough decision that Robert 
Running head: Mentor suitability and relationship quality.

had to make as to whether to reapply for his preferred course in the following year, or accept the place he had been offered on an alternative course, Anne said:

'I really felt it had to come from him, I felt there were pros and cons to both ways. I think getting himself back up to reapply, doing all that work over again, would have been quite hard and also then not knowing what to do in that interim year it would have been quite tough to keep motivated...and obviously there's no guarantee he would have got in the second time. I just said I'll be really happy to help if you decide to reapply, I'll be happy to help if that's what you want...I think in the end he thought, I've got this place, I'll go for that.'

Anne's young person-centred approach to working with Robert is in line with the recommendations emerging from US research on youth mentoring (Larose, Chaloux, Monaghan \& Tarabulsy, 2006), and demonstrates a high level of attunement (Pryce, 2012). Crucially, mentors at this level are able to cope with uncertainty at the beginning of a mentoring relationship, when mentor and mentee are negotiating their respective roles, understanding that the nature of mentoring is that each relationship will be unique. This ability is illustrated in Anne's description of the beginning of her work with Robert:

\footnotetext{
'it was quite difficult at first, because I wasn't sure how it was going to turn out, I wasn't sure what use I could be... and I could sense that he wasn't sure either, so both of us were very much "well let's just find out",
} 
Another indicator of Anne's young person-centred approach was her attitude to Robert at times when he did not take her advice. For instance, during their preparation for Robert's interview:

'I didn't want to overload him, but once he had got his Highers, I said they'll ask you about Curriculum for Excellence ${ }^{1}$, and tried to suggest things that he might read and websites to look at for that, and I think he maybe found that...a bit onerous, or a bit more work or whatever...he didn't really take that on so much'.

Anne demonstrates willingness to make suggestions as to how Robert should prepare for the interview without putting pressure on him to take her advice. In addition, when Robert is unsuccessful at the interview, Anne is non-judgemental as opposed to blaming him or overreacting to the disappointing result:

'Afterwards, even though he didn't get in, he was very appreciative and sent me a lovely email saying thankyou, and obviously he's now doing a great course, and...I think the interview just came a little bit early for him'.

This highlights another key aspect of mentoring, which is the support provided to young people when they are forced to adjust their expectations. At this stage, Anne is able to model a realistic attitude to the result, and support Robert in deciding what to do next. This helps to develop resilience, one of the key skills required to navigate through a Higher Education course and beyond.

\section{Relational learners}

\footnotetext{
${ }^{1}$ A Scottish Government initiative for education:
} http://www.educationscotland.gov.uk/learningandteaching/thecurriculum/whatiscurriculumforexcellence/index.asp 
Running head: Mentor suitability and relationship quality.

A second subset of volunteer mentors emerged in this project who demonstrated the ability to support young people in the same manner as 'relational experts', but may have had limited previous experience of doing so, and required more support to develop their confidence in the role. These individuals came from a range of professional backgrounds, and tended to have expertise in fields other than those directly involving relational work, or contact with young people. However, they had a clear interest in the relational aspects of mentoring, and the capacity to develop expertise in working with socially disadvantaged young people. For these mentors, support from the research team in relation to the emotional and psychological aspects of mentoring was necessary and often intensive, but given this support, mentoring relationships flourished.

Working with this group of mentors demonstrated that a model of mentoring for socially disadvantaged young people need not exclusively recruit volunteers with existing expertise in supporting vulnerable youth. In fact, the gap between relational experts and relational learners is only level of experience; the crucial factor which led to success for mentors from both of these groups was adaptability in relating to a young person. Those cases where taking part represented a new challenge to the mentor showed the value of developing relational capacity in interested volunteers, which has significant benefits for volunteer mentors and increases the sustainability of the project.

\section{Sarah and Vicky}

Sarah was an academic working in sociology who had experience of working on widening access processes in Higher Education. She was matched with Vicky, a pupil who had broad interests including history and architecture. According to teachers, Vicky had considerable 
difficulty in forming and maintaining peer relationships, and this difficulty seemed to translate into the mentoring relationship too. Sarah, after a first meeting with Vicky, described her as 'a feisty wee girl, and nothing wrong with that if it's channelled to realise achievement'. In the initial stages, Sarah experienced Vicky as disliking her, pushing her away and attempting to shock her. Vicky also used the mentoring project to skip classes, telling her teachers she was meeting her mentor when she wasn't. At the same time, Sarah was aware of Vicky being quite a high achiever academically and expressed some uncertainty about how she could add to that, saying 'there doesn't seem to be much room for improvement'. Sarah showed a high level of commitment to the project and to the relationship, but was at times distressed and concerned by Vicky's challenging behaviour, uncertain as to whether Vicky wanted to continue, and worried that she may not be able to help. Sarah noted:

'It was difficult at the beginning because I wasn't sure what my role was and how I could help. Actually I noted that some of the other mentors were retired teachers, and I think it can be really difficult for mentors who are non-teachers, and I didn't feel very well prepared for that. She was getting something like 18/20 for English essays, and I thought well I don't know anything about Higher English, how am I supposed to help? I think I learned that I can't just go straight to trying to improve her essay writing, there's more going on here'.

Through regular meetings with the research team, including one member with expertise in counselling young people, Sarah was encouraged to set clear boundaries with Vicky and within those boundaries to demonstrate patience and acceptance, aiming to convey her caring rather than collude with Vicky's pattern of relating. 
Running head: Mentor suitability and relationship quality.

The researcher discussed attachment theory with Sarah, pointing out that the reports from Vicky's teachers suggested that she may struggle to form attachments generally. Vicky's relational pattern seemed to involve testing another person's commitment to her by behaving in rejecting ways. In peer relationships, this had usually resulted in her becoming isolated from other young people. The researcher suggested that this pattern was being acted out with Sarah, and could begin to be overcome by responding differently, giving Vicky the experience of a different kind of relationship. Therefore, the importance of remaining committed to Vicky was clear. Sarah was open to this approach, and able to demonstrate her care and commitment to Vicky, but required some encouragement and support from the researchers that this was indeed the best way to approach the relationship. Following encouragement and reassurance from the research team, Sarah proceeded with confidence in her relationship with Vicky. Soon, a bond started to form between them:

'I think yesterday was a day to spill out feelings, and she talked about her mum leaving when she was seven. She went on to say how hard it was living with a dad and not a mum, and she has no one to talk to about female things. I just listened. I was very grateful that during the "testing time" with Vicky that I had persevered and didn't leave her as well'.

As Christmas approached, Sarah consulted the research team to ask for guidance as to whether or not it would be appropriate to give Vicky a small gift. Having discussed Vicky's interest in art with her during one mentoring session, Sarah wanted to give a sketch pad with charcoals. The researchers agreed that this inexpensive gift relating to one of Vicky's interests would be appropriate if Sarah wanted to make this gesture. Later, Sarah reported: 
'I gave it to her just before I left and she wouldn't stop crying because I had considered her worthy to give a present...it was hard not to cry myself. She is looking so much more relaxed with me and doesn't have the screwed up, strained face currently, although I should be under no disillusion that it may recur at any time. Moments like this should be treasured'.

Sarah's commitment to Vicky and ability to relate non-judgementally to her is clear, and demonstrates that mentor recruitment need not exclude applicants without prior experience working with vulnerable youth. This is consistent with Hirsch's (2005) advice that it is not essential for mentors to have prior experience of supporting young people, but it is beneficial to have sensitivity to the cultural and socioeconomic context of the young person. Sarah is able to tailor her skills to the specific mentoring relationship that she finds herself in, seeking support from the research team as appropriate and letting go of previous expectations for the project. For instance, when the match was made, Vicky had expressed an interest in sociology, which was Sarah's area of expertise. In practice, Vicky's interests moved towards history, while the mentoring role involved as much emotional support as career guidance. This example shows the importance of mentor attunement, given that the emotional challenges emerging from Sarah's relationship with Vicky could not have been anticipated by the research team at the time of introducing them. Volunteer mentors must be capable of coping with this level of emotional challenge in a mentoring relationship.

Having established a good working relationship, Sarah and Vicky were then able to begin work on the application process for a history degree at a prestigious university, and Sarah drew on her experience of widening access procedures to help Vicky navigate the different stages of the process. After Vicky succeeded in securing a place, Sarah continued to work with her in order to prepare her for the change in environment. 
Running head: Mentor suitability and relationship quality.

'I always had in the back of my mind that it wasn't just about getting a place, and also about how she would fare at university. I said to her 'in some ways it's really comfortable in school, and university will be very different. I knew from my background in widening access that Vicky would be in a minority having come from her school, and most of the other students would have a very different experience of life. People can feel quite alienated to begin with...I wanted her to know that she'll be in classes with people who are extremely confident. So we talked about leadership qualities and holding your own in a group without necessarily becoming dominant, because Vicky tends to shy away from speaking out and wants to blend into the background, which I thought could leave her quite isolated at university. I said 'you will come across people who dominate in a class, but lecturers will want to hear from everyone, and it's important to have your chance to speak'.

Again, the focus was on Vicky's emotional readiness for the university environment, developing her resilience and thinking about her long-term flourishing rather than just the first hurdle of achieving a place at University. This was in contrast to what Sarah had initially imagined mentoring would entail, i.e. a focus on academic issues, but she was able and willing to adapt her expectations and work with the research team to adjust her approach to working with Vicky.

\section{Non-relational mentors}

A third subset of volunteers were identified as non-relational in their approach to mentoring, and for this reason are not necessarily suited to the task, particularly with more vulnerable young people. These volunteers were often from high status professional backgrounds with 
an interest in contributing to the project by sharing their expertise, but appeared to lack an interest in, or awareness of, the relational aspects of mentoring. The motivation to focus solely on attainment and work towards clearly defined vocational goals may be helpful for particularly resilient and ambitious young people, but shows a lack of consideration of the broader social issues facing many young people, especially those living in areas of high social deprivation. Ideally, young people will be offered a strong relational bond with a mentor first and foremost, which then acts as a container for work towards educational and vocational goals as appropriate.

\section{Pauline and Grant}

One mentor whose approach was identified as non-relational was Pauline, a retired medical consultant, who was matched with Grant, who had broad career interests including Biochemistry. Despite being very academically able, Grant had problems motivating himself to attend classes and study, and was often supported by pastoral care staff (with whom he had good relationships). Pauline and Grant met regularly for one school year, and both reported satisfaction with the mentoring relationship. However, an interview with Pauline towards the end of the school year caused concern for the research and development team. This was primarily due to her lack of interest in forming an emotional connection with Grant, her adherence to a deficit model of academic success, and her somewhat dismissive attitude to Grant's personal goals and interests. A lack of relational skills on the part of the mentor is one factor identified by Spencer (2007) in a study of what happens when mentoring relationships end prematurely, and though this had not happened, the research and development team were concerned about how Pauline's approach might impact on Grant. For instance, Pauline focused to a large extent on assessing Grant's academic ability based on a binary understanding of intelligence (what she described as 'bright' vs. 'not bright'), and seemed preoccupied with whether or not Grant 'has what it takes'. After each 
Running head: Mentor suitability and relationship quality.

mentoring session, Pauline was in the habit of verifying Grant's own accounts of his academic progress with teaching staff, saying that she wanted to check whether Grant's reports of improvement were 'truth'. As well as the time demand this created for teaching staff, the research team were concerned that Pauline was overly concerned with the external reality of Grant's performance at school without attending to his experience. This attitude is in direct opposition to the young person-centred approach illustrated in the previous two cases, where the mentor adapts their expectations to the needs of the pupil, attempting to understand the young person's own frame of reference. At the same time, Pauline seemed dissatisfied with the project, frequently contacting the research team to question the purpose of mentoring and the suitability of Grant for the project. Although the research and development team spent time explaining the ethos of the project and the purpose of mentoring, Pauline's view did not change. As well as the afore-mentioned concern over assessing Grant's academic ability, she conversely questioned whether he needed any support academically. It seemed that since Grant presented as able and confident, and reported a strong motivation to study, achieve 5 Highers and apply to University, Pauline was unable to see any need for support. At organised events for mentors, Pauline often questioned whether Grant was 'socially disadvantaged' at all, and intimated that her expectations of mentoring had been quite different from the reality. Following unsuccessful attempts to explain the conceptual background of the mentoring project, the research team took this as further evidence of Pauline's commitment to a deficit model and unsuitability for the mentoring role.

Considering the evidence that mentoring relationships which end prematurely may be damaging to vulnerable youth, the research team developed a strategy to manage this case whereby Pauline and Grant continued to meet, while Grant was given additional input from 
a member of the research team trained in motivational interviewing. Meanwhile, both the research team and members of teaching staff worked with Pauline to challenge her approach and suggest a more young person-centred alternative, though there was no indication that this challenge was effective in terms of changing her views. In the following school year, Grant indicated that he would rather not continue with mentoring and Pauline was informed of this change. The teaching staff went on to support Grant as they had been, and the research team emphasised that he was welcome to rejoin the project at any time. Although this mentoring relationship lasted for the project's minimum requirement of one school year, it was not perceived by the research team to be a successful one, and highlighted the importance of making more careful decisions about mentor recruitment and training.

Implications for recruiting, training and supporting mentors

Training for volunteer mentors should be as extensive as possible, since the research evidence shows that satisfying, effective mentoring relationships are associated with greater time spent on mentor training (DuBois et al, 2002; Herrera et al, 2000). For instance, mentors who receive more training tend to spend more time with mentees (Herrera et al, 2000) and are more likely to continue into a second year (Herrera et al, 2007). In contrast, mentors with less training report low levels of closeness in their relationships with youth (Herrera et al, 2000).

Of the three mentors mentioned above, Anne (a relational expert) was the only one who required a standard level of training and support in order to fulfil her role. In planning the mentoring project with the resources that were available, a team of relational expert mentors would be necessary to allow adequate staff time for training and supporting mentors. Sarah (a relational learner) required more input from the research team in addition to the initial 
Running head: Mentor suitability and relationship quality.

training and standard level of support. This was partly a result of the particular needs of Vicky, her mentee, and partly her lack of previous experience in supporting a vulnerable young person. The successful mentoring relationship that was formed between Sarah and Vicky appeared to be beneficial for both of them, and demonstrates that the possibility of providing this kind of additional support should be built into a mentoring project at the planning stages to allow adequate resources to meet the need. Pauline, described here as a non-relational mentor, was deemed unsuitable for working with socially disadvantaged young people due to her lack of necessary relational skills and understanding of the social and cultural context.

Unfortunately, no foolproof method exists to determine at the recruitment stage which individuals will go on to display high levels of attunement in mentoring relationships. This process relies on the research team developing an accurate sense of an applicant's level of relational skill, understanding of social disadvantage, and adherence to the values of the project. For the most part, the experience of the Glasgow Intergenerational Mentoring Network has shown that a lack of relational skill on the part of the mentor tends to be already apparent to the research team at the interview stage, thus preventing a match which may not be beneficial for the young person. However, as in the case of Pauline and Grant, there are times when a mentor's unsuitability for the role becomes clear only after being matched with a young person. The course of action in this case was a result of discussion among the research team and the relevant teaching staff, and specific to the unique circumstances of the relationship. However, the case raises interesting questions about the potential harm of matching a young person with a volunteer who may be unsuitable for mentoring. Would ending this relationship prematurely have caused harm? Would Grant have benefited from being re-matched with a more suitable mentor? Although research has 
pointed to harm as a result of mentoring relationships which end prematurely, less is known about the impact of a situation where the duration and level of commitment may be adequate, but the quality of the relationship is in question. Further research is required on the types of mentoring relationship that may be formed, and the impact they may have on young people, both positive and negative.

\section{References}

Bandura, A. \& Locke, E.A. (2003). Negative Self-Efficacy and Goal Effects Revisited. Journal of Applied Psychology, 88 (1): 87-99.

Callahan, M. \& Lumb, C. (1995) My cheque and my children: the long road to empowerment in child welfare. Child Welfare, 73: 795-819.

Center for Prevention Research and Development. (2009). Background Research: Mentoring Programs. Champaign, IL: Center for Prevention Research and Development, Institute of Government and Public Affairs, University of Illinois.

Downey, G., Lebolt, A., Rincon, C. \& Freitas, A.L. (1998). Rejection Sensitivity and Children's Interpersonal Difficulties. Child Development, 69 (4): 1074-1091.

DuBois, D. L., Neville, H. A., Parra, G. R., \& Pugh-Lilly, A. O. (2002). Testing a new model of mentoring. In G. G. Noam (Ed.-in-chief) \& J. E. Rhodes (Ed.), A critical view of youth mentoring (New Directions for Youth Development: Theory, Research, and Practice, No. 93, pp. 21-57). San Francisco: Jossey-Bass. 
Running head: Mentor suitability and relationship quality.

DuBois, D. L., Portillo, N., Rhodes, J. E., Silverthorn, N. et al (2011). How effective are mentoring programs for youth? A systematic assessment of the evidence. Psychological Science in the Public Interest, 12, 57-91.

Eby, L; Allen, T; Evans, C, Thomas Ng, et al. (2008) Does mentoring matter? A multidisciplinary meta-analysis comparing mentored and non-mentored individuals. Journal of Vocational Behavior, 72, 254-267.

Garringer, M., Fulop, M., Rennick, V. (2003). Foundations of successful youth mentoring: A guidebook for program development. Portland, OR: National Mentoring Center.

Grossman, J. B. \& Rhodes, J. E. (2002). The test of time: Predictors and effects of duration in youth mentoring relationships. American Journal of Community Psychology, 30(2), $199 \square 219$.

Herrera, C., Sipe, C. L., \& McClanahan, W. S. (2000). Mentoring school-age children: Relationship development in community-based and school-based programs. Philadelphia: Public/Private Ventures. (Published in collaboration with MENTOR/National Mentoring Partnership, Alexandria, VA).

Herrera, C., Grossman, J. B., Kauh, T. J., Feldman, A. F., \& McMaken, J. (2007). Making a difference in schools: The Big Brothers Big Sisters school-based mentoring impact study. Philadelphia: Public/Private Ventures.

Hirsch, B. J. (2005). A Place to Call Home: After-school Programs for Urban Youth. Washington,DC: American Psychological Association and New York: Teachers College Press. 
Karcher, M. J. (2005). The effects of developmental mentoring and high school mentors' attendance on their younger mentees' self-esteem, social skills, and connectedness. Psychology in the Schools, 42, 6577.

Keller, T. (2005). The stages and development of mentoring relationships. In D. DuBois, \& M. Karcher (Eds.), The SAGE Program on Applied Developmental Science: Handbook of youth mentoring. (pp. 82100). Thousand Oaks, CA: SAGE Publications, Inc. doi: http://dx.doi.org/10.4135/9781412976664.n6

Larose, S. Savoie, J., DeWit, D.J., Lipman, E.L. \& DuBois, D.L. (2015). The role of relational, recreational, and tutoring activities in the perceptions of received support and quality of mentoring relationship during a community-based mentoring relationship. Journal of Community Psychology, 43 (5): 527-544.

Larose, S., Chaloux, N., Monaghan, D., \& Tarabulsy, G. M. (2006). Working alliance as a moderator of the impact of mentoring relationships among academically at-risk students. Manuscript submitted for publication.

Pryce, J. (2012). Mentor attunement: An approach to successful School-based Mentoring Relationships. Child and Adolescent Social Work Journal, 29: 285-305.

Rhodes, J. E. (2002). Stand by me: The risks and rewards of mentoring today's youth. Cambridge, MA: Harvard University Press

Rhodes, J. E. (2005). A theoretical model of youth mentoring. In D. L. DuBois \& M. J. Karcher (Eds.), Handbook of Youth Mentoring (pp. 30-43). Thousand Oaks, CA: Sage Publications, Inc

Rhodes, J. E., Liang, B., \& Spencer, R. (2009). First do no harm: Ethical principles for youth mentoring relationships. Professional Psychology: Research and Practice, 40, 452-458. 
Running head: Mentor suitability and relationship quality.

Rhodes, J. E., \& DuBois, D. L. (2008). Mentoring relationships and programs for youth. Current Directions in Psychological Science, 17, 254-258.

Saul, J., \& Audage, N.C. (2007). Preventing Child Sexual Abuse Within Youth-serving Organizations: Getting Started on Policies and Procedures. Atlanta (GA): Centers for Disease Control and Prevention, National Center for Injury Prevention and Control.

Shpigelman, C-N. \& Gill, C.J. (2013). The characteristics of unsuccessful e-mentoring relationships for youth with disabilities. Qualitative Health Research, 23 (4): 463-475.

Soucy, N. and Larose, S. (2000). Attachment and Control in Family and Mentoring Contexts as Determinants of Adolescent Adjustment to College. Journal of Family Psychology, 14(1): 125143.

Spencer, R. (2006). Understanding the mentoring process between adolescents and adults. Youth \&Society, 37(3), 287 $\square 287$.

Spencer, R. (2007). "It's not what I expected": A qualitative study of youth mentoring relationship failures. Journal of Adolescent Research, 22(4), 331-354.

World Health Organization (2010). Mental health: strengthening our response. Geneva: WHO. 